\title{
Biochemical Indicators as Predictive Markers by Combining Clinical Signs in Pre-eclampsia
}

\author{
Ana Daneva-Markova*, Katerina Nikolovska, Irena Aleksievska, Vlatko Girevski, Marija Joksimovikj \\ University Clinic of Gynecology and Obstetrics, Skopje, Republic of Macedonia
}

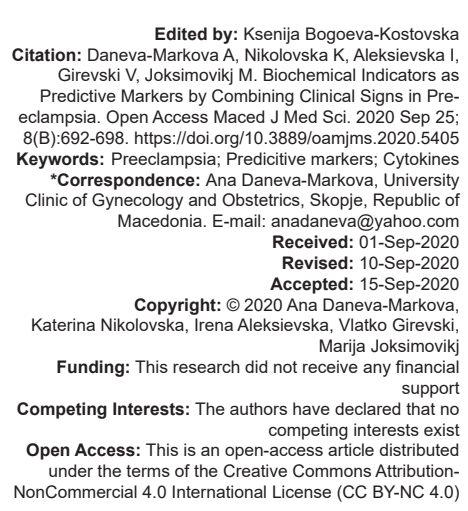

\section{Introduction}

Pre-eclampsia, defined as the onset of hypertension and the presence of protein in the urine at $>20$ weeks of gestation in a previously normotensive woman, is a pregnancy complication that is still one of the leading causes of death and disability of both mother and babies. Pre-eclampsia occurs in $5-8 \%$ of pregnancies in developed countries [1], [2], [3].

Risk factors for pre-eclampsia that have been identified in previous studies include both young and old maternal age, high BMI, prior pregnancy with preeclampsia, excessive weight gain during pregnancy, nulliparity, chronic hypertension, low socioeconomic status, prolonged birth interval, race and ethnicity, genetic predisposition, environmental, and even seasonal influences. Ironically, although smoking during pregnancy causes various adverse pregnancy outcomes when it comes to pre-eclampsia and hypertensive disorders in pregnancy, many studies have shown that it is associated with reduced risk [4], [5], [6].
The role of immune mechanisms contributing to the development of a normal pregnancy is widely discussed. Their involvement in the pathogenesis of pregnancy complications, such as pre-eclampsia, was also noted. The analysis of the scientific literature reveals the conclusion that many aspects of the pathogenesis of pre-eclampsia are related to systemic inflammatory response syndrome with the development of a destructive inflammatory process, immune disorders, and the imbalance of cytokine regulation of gestation processes [7], [8].

The role of vascular endothelial damage with the development of generalized arteriolar spasm as one of the leading mechanisms in the pathogenesis of preeclampsia is supposed to be significant. However, the relationship between the development of endothelial dysfunction and disruption of cytokine regulation in different clinical forms of pre-eclampsia also requires further research and is currently represented in several scientific works [9].

Proteinuria has been proposed and studied as both an indicator of the severity of the disease and 
as a predictor of the outcome in pre-eclampsia. Many clinicians still make major management decisions based on the degree of proteinuria in these patients.

The quantity of protein that is excreted in the urine varies widely. Significant protein excretion is defined as $\geq 300 \mathrm{mg}$ in a 24 -h urine collection or $1+$ or greater on urine dipstick testing of two random urine samples that are collected at least $4 \mathrm{~h}$ apart [10].

The serum uric acid level once was used as an indicator of pre-eclampsia, but it has been found to lack sensitivity and specificity as a diagnostic tool. However, an elevated serum uric acid level may be of some use in identifying pregnant women with chronic hypertension who have an increased likelihood of having superimposed pre-eclampsia.

A lactate dehydrogenase (LD or LDH) test is a non-specific test that may be used in the evaluation of a number of diseases and conditions. Thus, the blood level of LD is a general indicator of tissue and cellular damage and it is used as one of the indicators of pre-eclampsia. Several studies have confirmed the accentuation of platelet activation in pre-eclampsia which remains an important obstetric complication affecting $2-4 \%$ of all pregnancies. Detection of aberrations of platelet function and activation appears to have predictive value for the diagnosis [11].

Studies showed that in pregnancy complicated by pre-eclampsia, cytokine levels essentially change compared with the respective levels in physiological pregnancy. Thus, even a moderate form of preeclampsia shows directional change, that is, elevated levels of pro- and anti-inflammatory cytokines, with the exception of IL-10, wherein a downward trend in severe pre-eclampsia is recorded [10], [11].

We carried out this study to estimate the risk of developing different forms of pre-eclampsia for each demographic and clinical risk factor as to evaluate the relationship between the formation of anti-inflammatory IL10 cytokine and several indicators of moderate and severe pre-eclampsia.

This will provide an evidence base from which health-care professionals can assess each pregnant woman's risk of pre-eclampsia at her first antenatal visit and arrange her antenatal care according to need.

\section{Material and Methods}

Univariant logistic regression analysis was used for determination of the predictive role of certain sociodemographic, clinical, and biochemical parameters for severe pre-eclampsia.
Statistical data analysis was performed using the SPSS statistical package for Windows, version 13.0. Logistic regression analysis (binary logistic regression) was used to determine the predictive value of the different parameters for the occurrence of severe pre-eclampsia. Rates of probability - odds ratios (OR) and $95 \%$ confidence intervals $(\mathrm{Cl})$ were calculated to quantify independent associations.

\section{Results}

\section{Maternal age}

Maternal age of patients with non-severe and severe pre-eclampsia was analyzed into two categories: Older than 35 and younger than 35 years. The results showed that $16 \%$ from the patients with a non-severe form of pre-eclampsia and $52 \%$ form the patients with a severe form of pre-eclampsia were older than 35 years. The statistical analysis confirmed that pregnant women older than 35 years, highly significant, have a severe form of pre-eclampsia $(p=0.007)$ (Figure 1).

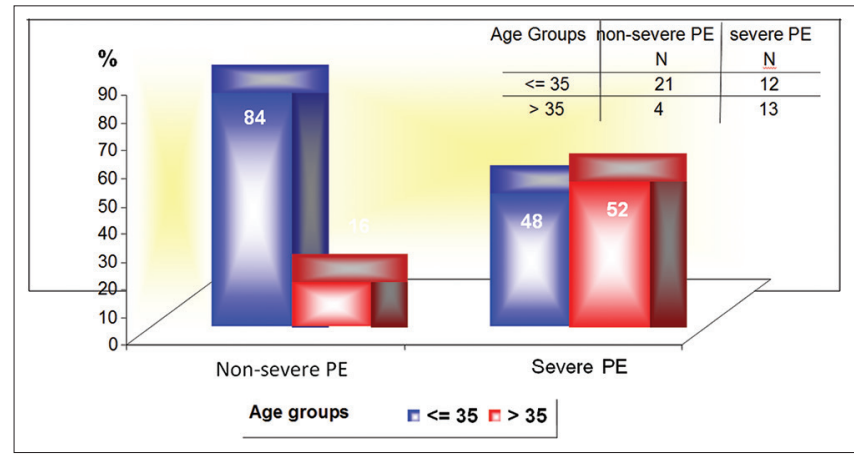

Figure 1: Age groups - non-severe and severe PE. Pearson Chisquare: $7.21 d f=1, p=0.007^{* *}, p<0.01$

The age of the respondents analyzed as a continuous variable has confirmed itself as a highly significant predictor for the severe form of eclampsia $(p=0.004)$. Advancing the age for another year increases the probability for getting a severe form of eclampsia during the pregnancy for $26.3 \%(95.0 \% \mathrm{Cl}$ 1.08-1.478) (Table 1).

Table 1: Univariant logistic regression analysis - the meaning of age in the prediction of severe eclampsia

\begin{tabular}{|c|c|c|c|c|c|c|}
\hline Variable & $\mathrm{B}$ & SE & Wald & Sig. & $\operatorname{Exp}(\mathrm{B})$ & $95.0 \% \mathrm{Cl}$ for $\operatorname{Exp}(\mathrm{B})$ \\
\hline Age & 0.234 & 0.080 & 8.510 & $0.004^{* *}$ & 1.263 & $1.080 \quad 1.478$ \\
\hline Constant & -7.510 & 2.603 & 8.323 & 0.004 & 0.001 & \\
\hline
\end{tabular}

The age analysis as a categorical variable in two age groups (older and younger than 35 years) has shown that pregnant women older than 35 years are in 5.687 times $(95.0 \% \mathrm{Cl} 1.510-21.424)$ bigger risk from the pregnant women aged 35 and younger to develop a severe form of gestosis (Tables 2 and 3). 
Table 2: Univariant logistic regression analysis - age over 35 years for prediction of severe eclampsia

\begin{tabular}{llllllll}
\hline Variable & B & SE & Wald & Sig. & Exp (B) & $95.0 \%$ Cl for Exp (B) \\
\hline Age $>35$ & 1.738234 & 0.677 & 6.599 & $0.01^{* *}$ & 5.687 & 1.510 & 21.424 \\
Constant & -0.56 & 0.362 & 2.391 & 0.122 & 0.571 & & \\
\multicolumn{7}{l}{ Dependent variable - severe eclampsia/medium eclampsia ${ }^{* \star} p<0.01}$.
\end{tabular}

\section{Gestation}

The probability for getting a severe form of preeclampsia insignificantly decreases with the increase of the gestation length of the pregnant women $(p=0.271)$. If the pregnancy continues for one more gestational week, the chance for getting a severe form of preeclampsia decreases for $8.8 \%(95.0 \% \mathrm{Cl} 0.775-1.74)$ (Table 3).

Table 3: Univariant logistic regression analysis - gestational age in the prediction for severe eclampsia

\begin{tabular}{llllllll}
\hline Variable & B & SE & Wald & Sig. & Exp (B) & $\mathbf{9 5 . 0 \% ~ C l ~ f o r ~ E x p ~ ( B ) ~}$ \\
\hline Gestation & -0.092 & 0.083 & 1.211 & 0.271 & 0.912 & 0.775 & 1.74 \\
Constant & 3.211 & 2.935 & 1.197 & 0.274 & 24.796 & & \\
\multicolumn{7}{l}{ Dependent variable - severe eclampsia/ medium eclampsia. }
\end{tabular}

\section{BMI}

For the level of significance of $p=0.05$, the results of the survey have confirmed the value of BMI as an insignificant factor for severe gestosis $(p=0.059)$ (Table 4).

Table 4: Univariant logistic regression analysis - BMI in the prediction of severe eclampsia

\begin{tabular}{llllllll}
\hline Variable & $\mathrm{B}$ & $\mathrm{SE}$ & Wald & Sig. & $\operatorname{Exp}(\mathrm{B})$ & $95.0 \%$ Cl for $\operatorname{Exp}(\mathrm{B})$ \\
\hline BMl & 0.131 & 0.070 & 3.562 & 0.059 & 1.140 & 0.995 & 1.307 \\
Constant & -4.505 & 2.407 & 3.504 & 0.061 & 0.011 & & \\
\multicolumn{7}{l}{ Dependent variable - severe eclampsia/ medium eclampsia. }
\end{tabular}

Dependent variable - severe eclampsia/ medium eclampsia.

\section{Nulliparity}

The nulliparity represents a highly significant risk factor for a severe form of pre-eclampsia $(p=0.006)$. Pregnant women without a history for previous delivery are in 5.63 times $(95.0 \% \mathrm{Cl} 1.648-19.232)$ higher risk than the pregnant women who previously gave birth for getting a severe form of pre-eclampsia (Table 5).

Table 5: Univariant logistic regression analysis - zero parity in the prediction of severe eclampsia

\begin{tabular}{llllllll}
\hline Variable & B & SE & Wald & Sig. & Exp (B) & $95.0 \%$ Cl for Exp (B) \\
\hline Zero parity & 1.728 & 0.627 & 7.600 & $0.006^{\star *}$ & 5.630 & 1.648 & 19.232 \\
Constant & -0.981 & 0.479 & 4.198 & 0.04 & 0.375 & & \\
\multicolumn{7}{l}{ Dependent variable - severe eclampsia/ medium eclampsia ${ }^{* *}$ p $<0.01}$.
\end{tabular}

\section{Number of pregnancies}

The number of pregnancies is an insignificant risk factor for a severe form of pre-eclampsia $(p=0.882)$. Pregnant women with two pregnancies have 0.857 times $(95.0 \% \mathrm{Cl} 0.111-6.617)$ insignificantly smaller chance than the ones with one pregnancy to develop a severe form of gestosis (Table 6).
Table 7: Univariant logistic regression analysis - previous preeclampsia in the prediction of severe eclampsia

\begin{tabular}{llllllll}
\hline Variable & B & SE & Wald & Sig. & Exp (B) & $95.0 \%$ Cl for Exp (B) \\
\hline Previous PE & 1.107 & 0.892 & 1.540 & 0.215 & 3.028 & 0.527 & 17.394 \\
Constant & -0.191 & 0.310 & 0.380 & 0.538 & 0.828 & & \\
\hline Depsta
\end{tabular}

Dependent variable - severe eclampsia/ non-severe eclampsia.

Table 6: Univariant logistic regression analysis - The number of pregnancies in the prediction of severe eclampsia

\begin{tabular}{llllllll}
\hline Variable & $\mathrm{B}$ & $\mathrm{SE}$ & Wald & Sig. & $\operatorname{Exp}(\mathrm{B})$ & $95.0 \% \mathrm{Cl}$ for Exp (B) \\
\hline Number of pregnancies & -0.154 & 1.043 & 0.022 & 0.882 & 0.857 & 0.111 & 6.617 \\
Constant & -1.099 & 0.667 & 2.716 & 0.099 & 0.333 & & \\
\hline
\end{tabular}

$\begin{array}{llllll}\text { Constant } & -1.099 & 0.667 & 2.716 & 0.099 & 0.333\end{array}$

Dependent variable - severe eclampsia/ non-severe eclampsia.

\section{Previous pre-eclampsia}

The results of our survey did not show that previous pre-eclampsia significantly increases the chance for getting a severe form of pre-eclampsia $(p=0.215)$. Pregnant women with a history for the previous pre-eclampsia have 3.028 times insignificantly larger probability from those with negative history for the previous pre-eclampsia to develop a severe form of gestosis (Table 7).

\section{Smoking status}

Smoking cigarettes insignificantly increases the risk for severe pre-eclampsia $(p=0.096)$. Pregnant women that are smokers are in 3.15 times insignificantly higher risk than the pregnant women that are nonsmokers for getting severe pre-eclampsia (Table 8).

Table 8: Univariant logistic regression analysis - previous preeclampsia in the prediction of severe eclampsia

\begin{tabular}{lllllllc}
\hline Variable & B & SE & Wald & Sig. & Exp (B) & $95.0 \%$ Cl for Exp (B) \\
\hline Smoker & 1.147 & 0.689 & 2.769 & 0.096 & 3.150 & 0.815 & 12.168 \\
Constant & -0.336 & 0.338 & 0.991 & 0.320 & 0.714 & & \\
\multicolumn{7}{l}{ Dependent variable - severe eclampsia/ non-severe eclampsia. }
\end{tabular}

\section{Diabetes mellitus}

Diabetes Type 1, Type 2, or gestation diabetes are insignificantly associated with a severe form of preeclampsia in the pregnancy $(p=0.364)$. The chances for getting severe eclampsia increase 2.3 times insignificantly for pregnant women with diabetes mellitus compared with pregnant women without diabetes (Table 9).

Table 9: Univariant logistic regression analysis - diabetes mellitus in the prediction of severe eclampsia

\begin{tabular}{llllllll}
\hline Variable & $\mathrm{B}$ & $\mathrm{SE}$ & Wald & Sig. & $\operatorname{Exp}(\mathrm{B})$ & $95.0 \% \mathrm{Cl}$ for Exp (B) \\
\hline Diabetes & 0.833 & 0.918 & 0.822 & 0.364 & 2.300 & 0.380 & 13.915 \\
Constant & -0.140 & 0.306 & 0.209 & 0.648 & 0.870 & & \\
\multicolumn{7}{l}{ Dependent variable - severe eclampsia/non-severe pre-eclampsia. }
\end{tabular}

\section{Systolic blood pressure}

Systolic blood pressure form $160 \mathrm{mmHg}$ and higher is measured at $20 \%$ from the group with a nonsevere form of eclampsia, and at $92 \%$ from the group with a severe form. The difference in the distribution of respondents with values of systolic blood pressure higher and lower than $160 \mathrm{mmHg}$ statistically is highly significant $(p=0.01)$ (Figure 2$)$. 


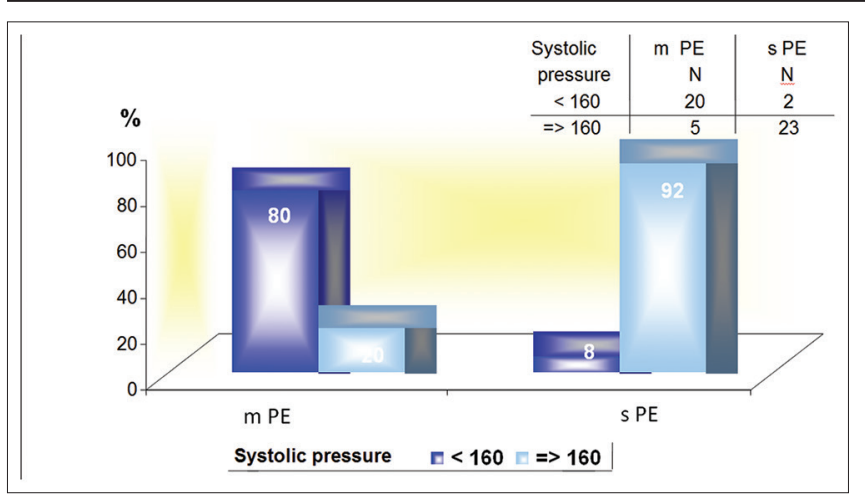

Figure 2: Systolic blood pressure - non-severe and severe PE. Pearson Chi-square: $26.29 d f=1, p=0.000^{\star *}, p<0.01$

Systolic blood pressure analyzed as a continuous variable has confirmed itself as a highly significant predictor for severe gestosis in pregnancy $(p=0.001)$. The increase of systolic blood pressure for $1 \mathrm{mmHg}$ 3a $25 \%(95.0 \% \mathrm{Cl} 1.009-1.423)$ increases the probability for severe eclampsia (Table 10).

Table 10: Univariant logistic regression analysis - systolic blood pressure in the prediction of severe eclampsia

\begin{tabular}{llllllll}
\hline Variable & $\mathrm{B}$ & $\mathrm{SE}$ & Wald & Sig. & $\operatorname{Exp}(\mathrm{B})$ & $95.0 \% \mathrm{Cl}$ for Exp (B) \\
\hline Systolic pressure & 0.224 & 0.066 & 11.464 & $0.001^{* *}$ & 1.250 & 1.099 & 1.423 \\
Constant & -35.524 & 10.558 & 11.321 & 0.001 & 0.000 & & \\
\hline Dependent variable - severe eclampsia/ non-severe eclampsia ${ }^{* *} \mathrm{p}<0.01$. & &
\end{tabular}

Pregnant women who have systolic blood pressure $160 \mathrm{mmHg}$ and higher have 46 times $(95.0 \% \mathrm{Cl}$ 8.027-1.423) significantly higher chance than pregnant women with systolic blood pressure lower than $160 \mathrm{mmHg}$ to develop a severe form of pre-eclampsia (Table 11).

Table 11: Univariant logistic regression analysis - systolic blood pressure higher than $160 \mathrm{mmHg}$ in prediction of severe eclampsia

$\begin{array}{lllllll}\text { Variable } & \text { B } & \text { SE } & \text { Wald } & \text { Sig. } & \text { Exp (B) } & 95.0 \% \text { Cl for Exp (B) }\end{array}$
\begin{tabular}{llllllll}
\hline Systolic pressure $>$ & 3.829 & 0.891 & 18.474 & $0.000^{* *}$ & 46.0 & 8.027 & 263.625
\end{tabular} $160 \mathrm{mmHg}$

$\begin{array}{llllll}-2.303 & 0.742 & 9.64 & 0.002 & 0.1\end{array}$

Dependent variable - severe eclampsia/ non-severe eclampsia.

\section{Diastolic blood pressure}

Diastolic blood pressure from $100 \mathrm{mmHg}$ and higher more often had the respondents from the group with severe pre-eclampsia compared with the ones from the group with non-severe pre-eclampsia (88\% vs. 44\%) (Figure 3).

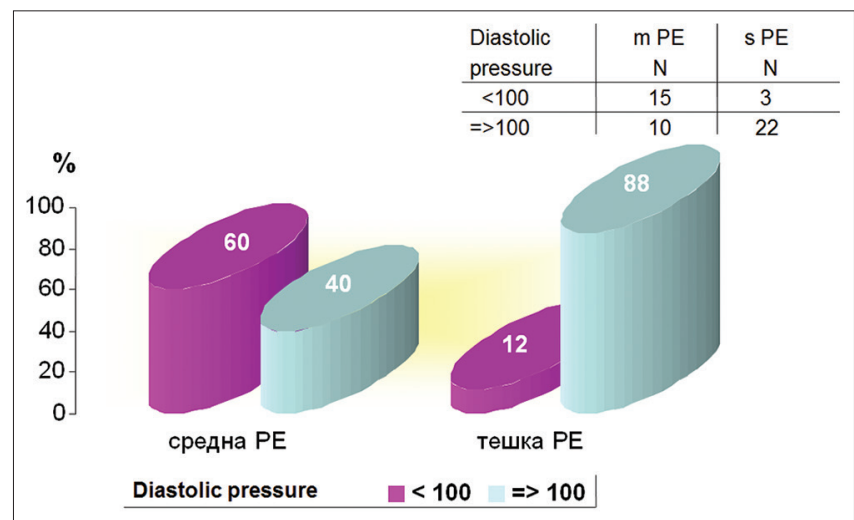

Figure 3: Diastolic blood pressure-medium and severe PE. Pearson Chi-square: $12.5, d f=1, p=0.0004^{* *}, p<0.01$
Diastolic blood pressure highly significant can predict the phenomenon of severe gestosis in pregnancy $(p=0.000)$. The increasing of the diastolic blood pressure for $1 \mathrm{mmHg}$ increases the probability for severe pre-eclampsia for $29.8 \%(95.0 \%$ Cl 1.129 1.492) (Table 12).

Table 12: Univariant logistic regression analysis - diastolic blood pressure higher than $160 \mathrm{mmHg}$ in the prediction of severe eclampsia

\begin{tabular}{lllllll}
\hline Variable & B & SE & Wald & Sig. & $\operatorname{Exp}(\mathrm{B})$ & $95.0 \% \mathrm{Cl}$ for $\operatorname{Exp}(\mathrm{B})$ \\
\hline
\end{tabular}
\begin{tabular}{llllllll}
\hline Diastolic pressure & 0.261 & 0.071 & 13.456 & $0.000^{* *}$ & 1.298 & 1.129 & 1.492
\end{tabular} $\begin{array}{llllll}\text { Constant } & -26.505 & 7.158 & 13.710 & 0.001 & 0.000\end{array}$

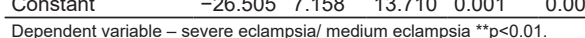

Pregnant women who have diastolic blood pressure $100 \mathrm{mmHg}$ and higher have 11 times significantly higher chance than pregnant women with diastolic blood pressure lower than $100 \mathrm{mmHg}$ to develop a severe form of eclampsia (Table 13).

Table 13: Univariant logistic regression analysis - diastolic blood pressure higher than $160 \mathrm{mmHg}$ in the prediction of severe pre-eclampsia

\begin{tabular}{llllllll}
\hline Variable & $\mathrm{B}$ & $\mathrm{SE}$ & Wald & Sig. & $\operatorname{Exp}(\mathrm{B})$ & $95.0 \% \mathrm{Cl}$ for Exp (B) \\
\hline Diastolic pressure & 2.398 & 0.739 & 10.541 & $0.001^{* *}$ & 11.0 & 2.587 & 46.779 \\
$\begin{array}{l}\Rightarrow \\
\text { C100 } \mathrm{mmHg}\end{array}$ & & & & & & & \\
Constant & -1.609 & 0.632 & 6.476 & 0.001 & 0.2 & & \\
\hline
\end{tabular}

Knowing that the pregnancy is a condition that requires immunological tolerance, it is widely accepted that immune mechanisms are involved in the pathogenesis of pregnancy complications such as pre-eclampsia. Studies showed that in pregnancy complicated by pre-eclampsia, cytokine levels essentially change compared with the respective levels in physiological pregnancy. Thus, even a moderate form of pre-eclampsia shows directional change, that is, elevated levels of pro- and anti-inflammatory cytokines, with the exception of IL-10, wherein a downward trend in severe pre-eclampsia is recorded.

The purpose of the actual study was to evaluate the relationship between the formation of anti-inflammatory IL10 cytokine and several indicators of moderate and severe pre-eclampsia in the third trimester of pregnancy.

Regarding patients' distribution by ethnicity, Albanians represented more than half of women with pre-eclampsia, as well as $44 \%$ of participants with symptoms of medium, and $68 \%$ with symptoms of severe PE. Pregnant Albanians (68\%) dominate in the group with normal tension.

The average BMI in the group of pregnant women with pre-eclampsia was $34.33 \pm 4.5$ that was not significantly higher than the average body mass of the control group (32.8 $8 \pm 3.8)$ ( $p=0.09)$. However, the difference between the average BMI of pregnant women with moderate and severe PE and normotensive pregnant patients was significant $(F=3.8, p=0.026)$. Namely, pregnant women with severe PE had significantly higher average BMI than normotensive pregnant women (35.57 \pm 4.1 vs. $32.88 \pm$ 3.8; $p=0.025)$ (Table 14). 
Table 14: Age, gestational week, BMI, and IL10 serum concentration in women with moderate and severe pre-eclampsia, and women with normal blood pressure (control group)

\begin{tabular}{|c|c|c|c|c|}
\hline \multirow[t]{2}{*}{ Variable } & \multicolumn{4}{|l|}{ Groups } \\
\hline & All PE $n=50$ & Moderate PE (mPE) $n=25$ & Severe PE (sPE) n=25 & Control $(C) n=50$ \\
\hline Age (years) mean $\pm S D$ & $32.06 \pm 4.8$ & $29.9 \pm 4.7$ & $34.2 \pm 3.85$ & $31.8 \pm 4.8$ \\
\hline \multicolumn{5}{|l|}{ All PE/C; $t=0.27 ; p=0.8$} \\
\hline $\mathrm{mPE} / \mathrm{sPE} / \mathrm{C} ; \mathrm{F}=5.5 ; \mathrm{p}=0.005$ & & Post hoc mPE/sPE $p=0.004$ & & \\
\hline Gestational week mean \pm SD & $34.99 \pm 3.5$ & $35.5 \pm 3.4$ & $34.4 \pm 3.6$ & $34.8 \pm 3.6$ \\
\hline \multicolumn{5}{|l|}{$\begin{array}{l}\text { All PE } / \mathrm{C} ; \mathrm{t}=0.2 ; p=0.8 \\
\mathrm{mPE} / \mathrm{sPE} / \mathrm{C} ; \mathrm{F}=0.6 ; p=0.5\end{array}$} \\
\hline \multicolumn{5}{|l|}{ Ethnicity $n(\%)$} \\
\hline Macedonian & $18(36)$ & $10(40)$ & $8(32)$ & $15(30)$ \\
\hline Albanian & $28(56)$ & $11(44)$ & $17(68)$ & $34(68)$ \\
\hline Romani & $4(8)$ & $4(16)$ & 0 & $1(2)$ \\
\hline BMI mean $\pm S D$, range & $34.33 \pm 4.5,24.2-44$ & $33.1 \pm 4.7,24.2-41$ & $35.57 \pm 4.1,27-44$ & $32.88 \pm 3.8,27-43.9$ \\
\hline
\end{tabular}

Table 15: Multivariate logistic regression analysis for the factors predictors of severe pre-eclampsia

\begin{tabular}{|c|c|c|c|c|c|c|c|}
\hline Variable & $\mathrm{B}$ & SE & Wald & p-value & $\operatorname{Exp}(\mathrm{B})$ & \multicolumn{2}{|c|}{$95 \% \mathrm{Cl}$ for $\operatorname{Exp}(\mathrm{B})$} \\
\hline Age (years) & 0.2 & 0.086 & 5.350 & 0.021 & 1.221 & 1.031 & 1.446 \\
\hline Nulliparity (present) & 1.816 & 1.114 & 2.657 & 0.103 & 6.145 & 0.692 & 54.534 \\
\hline Systolic blood pressure $(\geq 160 \mathrm{mmHg})$ & 3.711 & 1.053 & 12.412 & $<0.001$ & 40.9 & 5.189 & 322.371 \\
\hline Diastolic blood pressure ( $\geq 100 \mathrm{mmHg}$ ) & 2.414 & 0.843 & 8.192 & 0.004 & 11.176 & 2.140 & 58.360 \\
\hline Proteinuria (present) & 3.081 & 1.307 & 5.56 & 0.018 & 21.785 & 1.682 & 282.123 \\
\hline $\mathrm{LDH} \geq 450(\mathrm{U} / \mathrm{L})$ & 2.066 & 0.915 & 5.102 & 0.024 & 7.896 & 1.314 & 47.433 \\
\hline Albumin (serum) (g/L) & -0.239 & 0.125 & 3.66 & 0.056 & 0.787 & 0.616 & 1.006 \\
\hline Creatinine (serum) (umol/L) & -0.067 & 0.035 & 3.696 & 0.055 & 0.935 & 0.873 & 1.001 \\
\hline Platelets $(\leq 150000)$ & -0.006 & 0.013 & 0.236 & 0.627 & 0.994 & 0.97 & 1.019 \\
\hline IL10 (pg/ml) & -2.324 & 1.051 & 4.888 & 0.027 & 0.098 & 0.012 & 0.768 \\
\hline
\end{tabular}

Dependent variable: Severe pre-eclampsia.

Statistical analysis showed no significant differences in the levels of IL10 in serum between pregnant women with pre-eclampsia and healthy pregnant women $(p=0.5)$, but the difference between moderate pre-eclampsia, severe pre-eclampsia, and control group was highly significant $(p<0.01)$ due to the lower levels of this interleukin in severe pre-eclampsia group, comparing moderate pre-eclampsia in relation to the control, and due to the highly significant lower values when comparing control in relation to moderate pre-eclampsia group. Average concentrations of IL10 in serum were 23.2 \pm 40.7 $\mathrm{pg} / \mathrm{ml}$ in the total group of pre-eclampsia patients, $45.5 \pm$ $48.4 \mathrm{pg} / \mathrm{ml}$ in the group with moderate pre-eclampsia, and $0.8 \pm 0.4 \mathrm{pg} / \mathrm{ml}$ in the group with severe pre-eclampsia. In patients with normal-tension, the average serum concentration of IL10 was $4.2 \pm 6.7 \mathrm{pg} / \mathrm{ml}$.

Study data demonstrated that in pregnant women with pregnancy complicated by pre-eclampsia, the serum concentration of anti-inflammatory IL10 is confirmed as a significant predictor of the occurrence of severe pre-eclampsia. Increased serum concentrations of IL10 (in pg/mL) reduced the likelihood of the development of severe pre-eclampsia by $89.6 \%$ (95\% Cl 0.016-0.678).

Figures 4-6 show the results of bivariate analysis of the relationships between serum maternal concentration of IL10 and serum enzyme LDH, creatinine, platelets, proteinuria, and uric acid, respectively.

The obtained values of Pearson's coefficients indicate negative correlations of IL10 with $\mathrm{LDH}$ and proteinuria, whereas the correlations of IL10 with creatinine, platelets, and uric acid were positive. However, significant correlations were confirmed only between IL10 and platelets as well as between IL10 and proteinuria. The correlation with the platelet count was positive which means that significantly higher concentration of IL10 was confirmed in patients with a

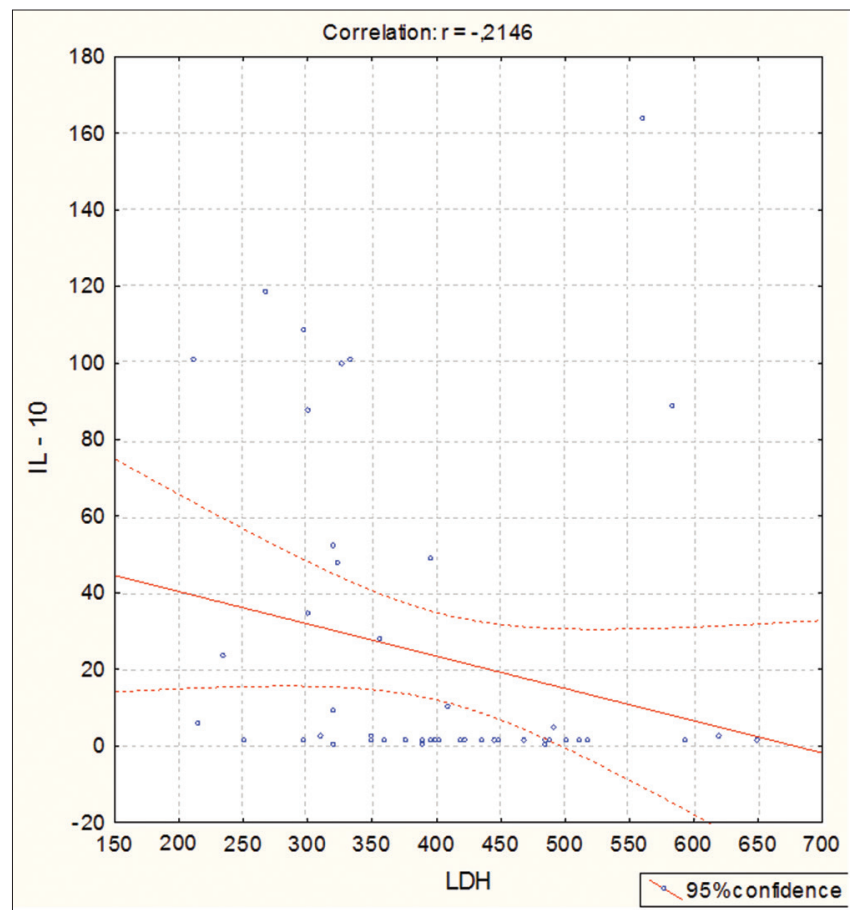

Figure 4: Correlation IL10/LDH. $r=-0.215 ; p=0.134$

higher number of platelets in the blood, and vice versa. The correlation between IL10 and proteinuria was negative, showing that the serum concentration of IL10 was significantly lower in patients with a higher amount of proteins in the urine, and vice versa.

\section{Discussion}

This study demonstrates differences in IL10 levels in women with pre-eclampsia compared to the levels in women with a normal pregnancy outcome. 


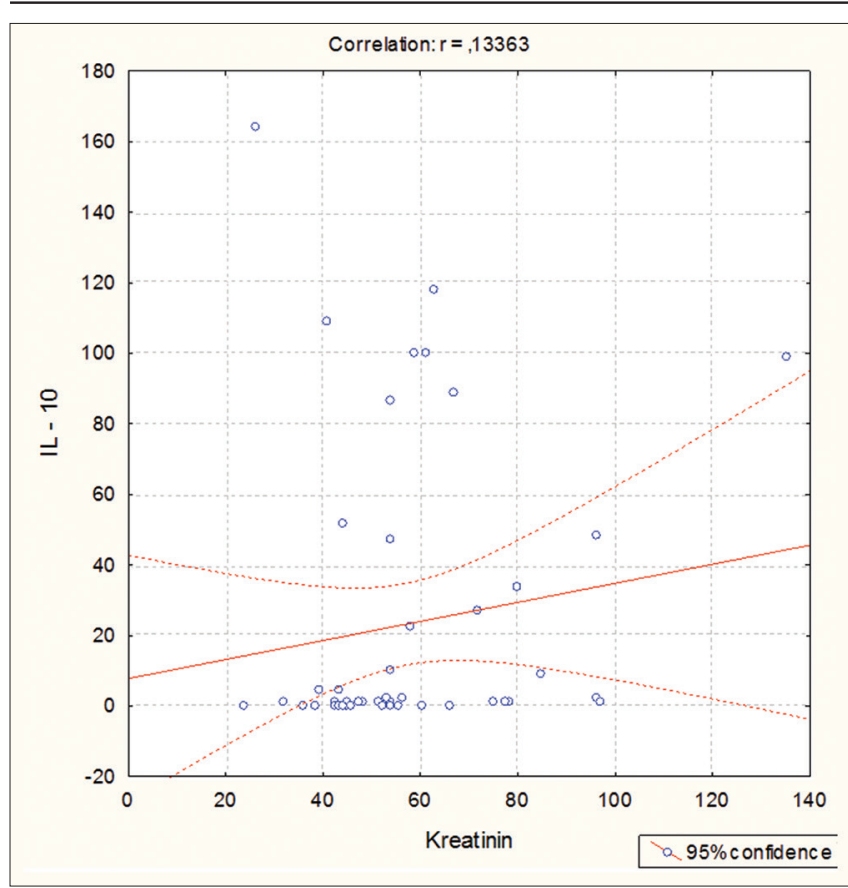

Figure 5: Correlation IL10/creatinine. $r=0.134 ; p=0.355$

We found that in pregnant women with preeclampsia, the increased serum concentrations of IL10 predicted a lower likelihood for the development of severe pre-eclampsia. IL10 has been identified as an important cytokine in pregnancy. It may be involved in the maintenance of pregnancy by corpus luteum maturation and progesterone production [12]. Ovarian corpus luteum cell growth was stimulated by exogenous IL10 and also in the presence of Th2 type lymphocytes derived during early pregnancy. In a well-known mouse cross that is prone to spontaneous abortion, a deficiency of IL10 has been demonstrated to alter the net fetal number and outcome [13]. Longitudinal studies in mice demonstrate a sequential change in the cytokine profile, including IL10 in peripheral blood and release from spleen elements as pregnancy advances [14], [15]. IL10 inhibition in the second half of pregnancy in mice causes fetal growth retardation [16]. Progesterone has been shown to increase Th2-type responses in T cells [17]. Taken together, these data suggest that early pregnancy is associated with an increase in circulating Th2 cytokine IL10.

This study demonstrated that there is a significant alteration in the serum concentration of IL10 in severe pre-eclampsia compared with normal pregnancy and in moderate pre-eclampsia groups of patients.

The regression analysis applied in this study showed systolic blood pressure of $160 \mathrm{mmHg}$ or higher, diastolic blood pressure of $100 \mathrm{mmHg}$ or higher, persistent proteinuria in pregnancy, the serum $\mathrm{LDH}$ concentration of $450 \mathrm{U} / \mathrm{L}$ or higher and reduced serum concentrations of IL10 as significant predictors of severe pre-eclampsia in pregnant women. While other variables predicted a higher likelihood for the

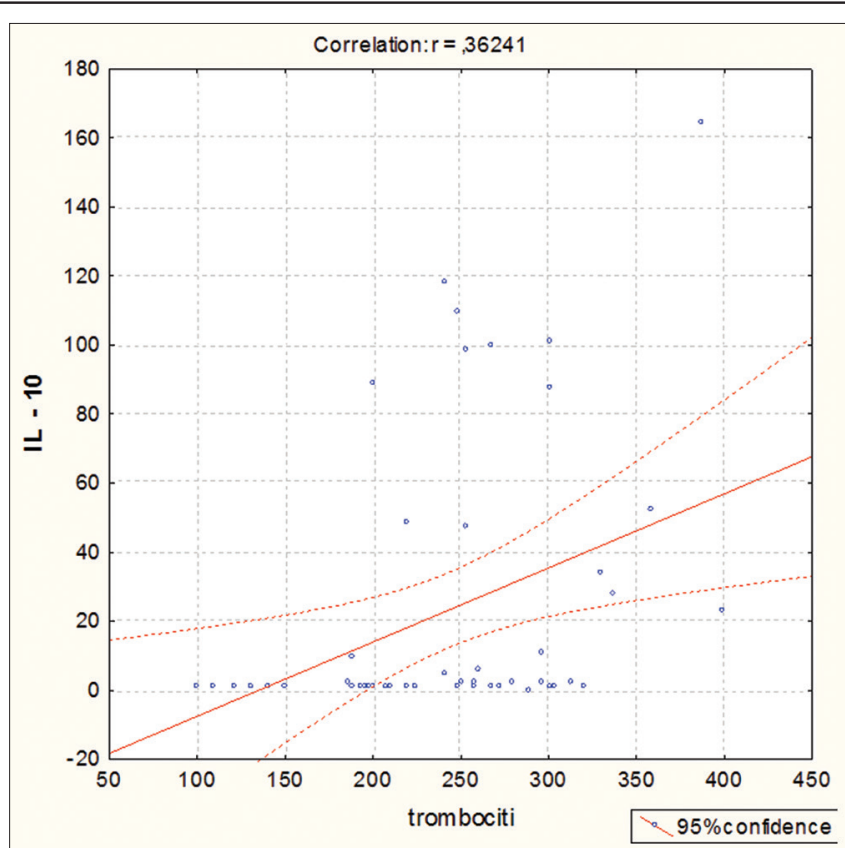

Figure 6: Correlation IL10/platelets. $r=0.362 ; p=0.01$

development of severe pre-eclampsia, IL10 decreased such likelihood. IL10 was also found to be negatively correlated with proteinuria and positively correlated with blood platelets. Significantly higher concentration of IL10 was confirmed in patients with a higher number of platelets in the blood, and vice versa. On the other hand, the serum concentration of IL10 was significantly lower in patients with a higher amount of proteins in the urine, and vice versa (Table 15).

The actual study demonstrated platelet count and proteinuria as significant predictors of serum IL10 concentration - platelets count predicting higher serum concentration of IL10, while urine proteins predicting lower serum IL10.

Some studies suggest a proportional link between the level of proteinuria and adverse clinical outcomes. Page et al., in a prospective study of almost 13,000 pregnant women, found that significant proteinuria, defined as 2+ or more on dipstick analysis, was associated with an increase in stillbirth rates, fetal growth restriction, and neonatal morbidity when associated with hypertension [18]. Other studies suggest that it is the presence of proteinuria rather than the severity, which is associated with poorer outcomes. There is evidence that even the finding of trace proteinuria in pregnant women with hypertension is associated with an increase in an adverse outcome.

Taking into consideration changes of antiinflammatory cytokine concentrations in severe preeclampsia, a moderate phase can be analyzed as a critical stage in complicated pregnancies.

It can be assumed that moderately aggressive factors have a role as initiators of synthesis of mediators of intercellular interaction (in moderate pre-eclampsia) 
and the development of immune response is regulated by the interaction of cytokines and their antagonists. With the increasing severity of the pathological process, the impact of regulatory factors that limit the systemic effect is reduced.

\section{References}

1. Quan LM. An analysis of the risk factors of preeclampsia and prediction based on combined biochemical indexes. Kaohsiung J Med Sci. 2018;34(2):109-12.

\section{PMid:29413226}

2. Rosser ML, Katz NT. Preeclampsia: An obstetrician's perspective. Adv Chronic kidney Dis. 2013;20(3):287-76. PMid:23928395

3. Raghupathy R. Cytokines as key players in the pathophysiology of preeclampsia. Med Princ Pract. 2013;22(1):8-19. PMid:23949305

4. Naljayan MV, Karumanchi SA. New developments in the pathogenesis of preeclampsia. Adv Chronic kidney Dis. 2013;20(3):265-70.

PMid:23928392

5. Tsatsaris V, Fournier T, Winer N. Pathophysiology of preeclampsia. Eur J Obstet Gynecol Reprod Biol. 2008;1:16-23.

6. LewisDF, CanzoneriBJ,WangY.MaternalcirculatingTNF-alphalevels are highly correlated with IL-10 levels, but not IL-6 and IL-8 levels, in women with pre-eclampsia. Am J Reprod Immunol. 2009;62(5):26974. https://doi.org/10.1111/j.1600-0897.2009.00735.x PMid:19706021

7. Sukhih GT, Vanko LV. Immune factors in the etiology and pathogenesis of pregnancy complications. Obstet Gynecol. 2012;1:128-36.

8. Makarov IO, Shemanaeva TV, Hasanov SR, Popova OP. Preeclampsia as a manifestation of immune endotheliosis. Quest Gynecol Obstet Perinatol. 2009;6:17-22

9. Tosun M, Celik H, Avci B, Yavuz E, Alper T, Malatyalioğlu E. Maternal and umbilical serum levels of interleukin-6, interleukin-8, and tumor necrosis factor-alpha in normal pregnancies and in pregnancies complicated by preeclampsia. J Mater Fetal Neonatal Med. 2010;23(8):880-6. https://doi. org/10.3109/14767051003774942

PMid:20441409

10. Bosio PM, McKenna PJ, Conroy R, O'Herlihy C. Maternal central hemodynamics in hypertensive disorders of pregnancy. Obstet Gynecoll. 1999;94(6):978-84. https://doi.org/10.1016/ s0029-7844(99)00430-5

\section{PMid:10576186}

11. Hashii K, Fujiwara S, Yoshioka N, Kataoka S, Yamada T, Hirano T. Peripheral blood mononuclear cells stimulate progesterone production by luteal cells derived from pregnant and nonpregnant women: Possible involvement of interleukin-4 and interleukin-10 in corpus luteum function and differentiation. Hum Reprod. 1998;13(10):2738. https://doi.org/10.1093/ humrep/13.10.2738

PMid:9804222

12. Piccinni MP, Giudizi G, Biagotti R, Beloni L, Giannarini L. Progesterone favors the development of human $T$ helper cells producing Th2 type cytokines and promotes both IL-4 production and membrane CD30 expression in established Th1 cell clones. J Immunol. 1995;155(1):128.

PMid:7541410

13. Chaouat G, Meliani J, Martal R. IL-10 prevents naturally occurring fetal loss in the CBA $\times$ DBA/2 mating combination, and local defect in IL-10 production in this abortion-prone combination is corrected by in vivo injection of IFN-tau. J Immunol. 1995;154(9):4261-8. https://doi.org/10.4049/ jimmunol.175.5.3447-d

PMid:7722286

14. Delassus S, Coutinho C, Saucier C, Darche S, Kourilsky P. Differential cytokine expression in maternal blood and placenta during murine gestation. J Immunol. 1994;152(5):2411-20.

PMid:8133052

15. Athanassakis I, Iconomidou B. Cytokine production in the serum and spleen of mice from day 6 to 14 of gestation: Cytokines/ placenta/spleen/serum. Dev Immunol. 1996;4(4):247-55. https://doi.org/10.1155/1995/42412 PMid:8924760

16. Rijhsinghani AG, Thompson K, Tygrette L, Bhatia SK. Inhibition of interleukin-10 during pregnancy results in neonatal growth retardation. Am J Reprod Immunol. 1997;37(3):232-5. https:// doi.org/10.1111/j.1600-0897.1997.tb00220.x

PMid:9127644

17. Côté AM, Firoz T, Mattman A, Lam EM, von Dadelszen P, Magee LA. The 24-hour urine collection: Gold standard or historical practice. Am J Obstet Gynecol. 2008;199(6):625.e1-6. https:// doi.org/10.1016/j.ajog.2008.06.009 PMid:18718568

18. Chen BA, Parviainen K, Jeyabalan A. Correlation of catheterized and clean catch urine protein/creatinine ratios in preeclampsia evaluation. Obstet Gynecol. 2008;112(3):606-10. https://doi. org/10.1097/aog.0b013e3181827c89

PMid:18757659 